\title{
Atributos físicos e fluxo de água em solos da bacia hidrográfica do rio Vacacaí-Mirim - RS
}

\author{
Physical properties and water flow in soils of river basin Vacacaí-Mirim - RS
}

\author{
Alencar Simão Rizzardi', Afranio Almir Righes², Pedro Daniel da Cunha Kemerich ${ }^{3}$, \\ Rodrigo Ferreira da Silva ${ }^{4}$, Sizabeli Amaral dos Santos ${ }^{5}$, Willian Fernando de Borba ${ }^{6}$ \\ ' Graduado em Engenharia, Habilitação Engenharia Ambiental, Centro Universitário Franciscano, Santa Maria, Brasil. \\ ${ }^{2}$ Professor no curso de Engenharia Ambiental e Sanitária, Centro Universitário Franciscano, Santa Maria, Brasil. \\ ${ }^{3}$ Coordenador do Curso de Engenharia Ambiental da Universidade Federal de Santa Maria/CESNORS, Frederico Westphalen, Brasil. \\ ${ }^{4}$ Programa de Pós-graduação em Agronomia: Agricultura e Ambiente, Universidade Federal de Santa Maria/CESNORS, Frederico Wes- \\ tphalen, Brasil. \\ ${ }^{5}$ Universidade Federal de Santa Maria, Santa Maria, Brasil. \\ ${ }^{6}$ Técnico em Agropecuária, Aluno de Graduação do Curso de Engenharia Ambiental, Universidade Federal de Santa Maria, Santa Maria, \\ Brasil.
}

\section{Resumo}

Variações na taxa de infiltração de água no solo por ações antrópicas têm alterado o fluxo de água em bacias hidrográficas. Atributos físicos como densidade do solo, macro e microporosidade e condutividade hidráulica saturada estão relacionadas a essas alterações. Com a finalidade de avaliar os solos que apresentam características hidrológicas favoráveis à recarga da água subterrânea, foram coletadas amostras na camada superficial de nove solos da Bacia Hidrográfica do Rio Vacacaí-Mirim-RS. Para as determinações de textura do solo e densidade de partículas foram utilizadas amostras com estrutura deformadas. As amostras não deformadas para densidade do solo, porosidade total, microporosidade, macroporosidade e condutividade hidráulica saturada $(\mathrm{K}(\mathrm{o})$ ). Os dados dos atributos físicos e hídricos dos solos foram submetidos a análises de correlação e regressão, relacionando-os com a condutividade hidráulica saturada do solo. Os resultados indicam que baixos valores de densidades do solo e altos valores de porosidade total proporcionam maior capacidade de fluxos de água da camada superficial em direção aos aquíferos da bacia estudada.

Palavras-chave: Parâmetros físicos e hídricos; Recarga de aquífero; Condutividade hidráulica saturada

\begin{abstract}
Changes on water infiltration rate into the soil by human activities have altered the water flow in watersheds. Physical soil attributes such as bulk density, macro and micro porosity and saturated hydraulic conductivity are related to these changes. In order to evaluate the soils with hydrological characteristics that are favorable for groundwater, samples were collected in the surface layer of nine soil son River Basin Vacacaí-Mirim - RS. Soil texture and particle density determinations were made using soil samples with deformed structure. And undisturbed soil samples were used for bulk density, porosity, microporosity, macroporosity and saturated hydraulic conductivity ( $\mathrm{K}(\mathrm{o})$ ). The results indicate that soils with low values of bulk density and high values of total porosities provide larger water flow capacity throughout the soil surface layer toward the aquifers of the study area.
\end{abstract}

Keywords: Physical parameters and water; Aquifer recharge; Saturated hydraulic conductivity 


\section{INTRODUÇÃO}

Variações na taxa de infiltração de água no solo por ações antrópicas têm alterado o fluxo de água em bacias hidrográficas. Períodos de secas e enchentes têm ocorrido com maior frequência nos últimos anos. Sendo assim, as alterações dos atributos físicos como a densidade do solo, macro e microporosidade e condutividade hidráulica saturada estão relacionadas ao problema.

Das propriedades do solo que mais influenciam na dinâmica da água, destaca-se a condutividade hidráulica saturada $(\mathrm{K}(\mathrm{o}))$. Ela é um parâmetro que demonstra a velocidade com que a água se movimenta ao longo do perfil do solo (MARQUES, 2008). Sua determinação, principalmente em áreas de recargas de importantes aquíferos, torna-se imprescindível, visto que a movimentação da água é um parâmetro que demonstra a rapidez com que o solo conduz a água. De tal modo, o conhecimento desta propriedade nos diferentes tipos de solos que constituem a bacia hidrográfica, reveste-se da mais alta importância, quando a intenção é estudar o fluxo saturado de água no solo para a recarga de aquíferos subterrâneos.

Entre os parâmetros físicos de solo para fins de drenagem, a condutividade hidráulica saturada do solo $(\mathrm{K}(\mathrm{o}))$, determinada a campo, tem a maior importância no dimensionamento e planejamento da drenagem interna do solo. De acordo com BELTRÁN (1986), $\mathrm{K}(\mathrm{o})$ depende da fluidez da água, que é proporcional a sua viscosidade e densidade, e da macroporosidade do solo que, por sua vez, é função da textura e da estrutura. Dentre os atributos do solo que interferem na condutividade hidráulica do solo saturado, a porosidade é uma das características mais importantes, visto que a água escoa pelos seus espaços vazios.

A condutividade hidráulica é afetada por diversos fatores inerentes ao solo. Pode-se destacar entre eles o tamanho de partículas, o índice de vazios, a estrutura, a estratificação e o grau de saturação do solo (LAMBE, 1974). A estrutura interna do solo é uma das características mais importantes que pode influenciar na $\mathrm{K}(\mathrm{o})$, principalmente em solos com texturas argilosas e siltosas, ficando difícil analisar esses fatores separadamente, já que estão intimamente relacionados.

O valor máximo de condutividade hidráulica é atingido quando o solo se encontra saturado, sendo denominado de condutividade hidráulica saturada (REICHARDT, 2005). A partir do solo saturado e empregando modelos matemáticos pode-se determinar a $\mathrm{K}(\mathrm{o})$ do solo e obter informações sobre o movimento de água e solutos nos solos.

As atividades antrópicas como arações, gradagens e cultivo, em geral, alteram a estrutura original da camada superficial interferindo no fluxo de água no perfil do solo. Com base no exposto o trabalho teve por objetivo definir os solos que apresentam características hidrológicas favoráveis para a recarga dos aqüíferos da Bacia Hidrográfica do Rio Vacacaí-Mirim-RS. Determinar a classificação textural dos principais solos, quantificar a condutividade hidráulica saturada do horizonte superficial dos tipos de solos selecionados e quantificar os atributos físicos mais importantes destes solos e suas relações com a condutividade hidráulica saturada.

\section{MATERIAIS E MÉTODOS}

O trabalho foi desenvolvido na Bacia Hidrográfica do Rio Vacacaí-Mirim, localizada na Depressão Central do Estado do Rio Grande do Sul, entre as coordenadas geográficas de $29^{\circ} 36^{\prime} 55^{\prime \prime}$ e $29^{\circ} 39^{\prime} 50^{\prime \prime}$ de latitude Sul, e 5346'30" e 5349'29" de longitude Oeste pertencente a Região Hidrográfica do Guaíba, abrangendo área de 1.145,7 Km2.

\section{SOLOS AMOSTRADOS}

No trabalho, buscou-se identificar os principais solos de ocorrência na Bacia Hidrográfica do Rio Vacacaí-Mirim que apresentassem diferentes classes texturais em suas condições naturais, com ampla variação de seus atributos físicos. Foram selecionados nove solos classificados segundo o Sistema Brasileiro de Classificação de Solos (EMBRAPA, 1999) em: ALISSOLOS, ARGISSOLOS e NEOSSOLOS.

\section{AMOSTRAGEM}

Amostras de solo com estrutura deformada e não deformada foram coletadas, em locais representativos da bacia hidrográfica. Considerando que as alterações antrópicas ocorrem na camada superficial dos solos, a amostragem foi realizada na camada de 0 a $20 \mathrm{~cm}$ de profundidade (Figura 1). As descrições de cada local de amostragem com sua respectiva localização são apresentadas na tabela 1 .

Para a coleta das amostras, foi removida a vegetação da camada superficial de solo. As coletas das amostras foram realizadas quando os solos se apresentavam-se com conteúdo de água aproximadamente abaixo da capacidade de campo (48 horas após período de chuva). Esse é um aspecto importante a ser observado durante o processo de coleta com estrutura não deformada, uma vez que o solo muito úmido adere ao anel e, quando muito seco, racha e se desestrutura. 
Tabela 1. Coordenadas Geográficas dos pontos de coleta, altitude e respectivas classificações dos solos coletados na bacia hidrográfica do Rio Vacacaí Mirim-RS, Santa Maria 2010.

\begin{tabular}{ccccc}
\hline \multirow{2}{*}{ Solos } & \multicolumn{2}{c}{ Coordenadas UTM } & Altitude (m) & Classificação \\
\cline { 2 - 4 } & Latitude & Longitude & & \\
\hline 1 & $6712510,38 \mathrm{~S}$ & $231523,28 \mathrm{~L}$ & 119,1 & Argissolos \\
2 & $6717386,31 \mathrm{~S}$ & $233305,10 \mathrm{~L}$ & 389,1 & Neossolos \\
3 & $6724273,47 \mathrm{~S}$ & $232012,47 \mathrm{~L}$ & 464,5 & Argissolos \\
4 & $6726697,03 \mathrm{~S}$ & $245373,23 \mathrm{~L}$ & 481,6 & Argissolos \\
5 & $6721806,00 \mathrm{~S}$ & $249539,80 \mathrm{~L}$ & 487,5 & Neossolos \\
6 & $6709946,89 \mathrm{~S}$ & $237538,79 \mathrm{~L}$ & 91,7 & Argissolos \\
7 & $6708800,05 \mathrm{~S}$ & $235364,36 \mathrm{~L}$ & 109,6 & Argissolos \\
8 & $6702202,53 \mathrm{~S}$ & $242691,98 \mathrm{~L}$ & 140,7 & Argissolos \\
9 & $6703803,01 \mathrm{~S}$ & $257397,19 \mathrm{~L}$ & 87,6 & Alissolo \\
\hline
\end{tabular}

As amostras de solo com estrutura não deformada foram obtidas com o auxílio de amostrador tipo Uhland e anéis Kopeck destinados às determinações de densidade e porosidade do solo. As amostras destinadas às determinações da condutividade hidráulica do solo saturado foram coletadas em cilindros de Uhland com dimensões de 7,0 cm de diâmetro e 7,0 $\mathrm{cm}$ de altura. Para cada um dos nove solos amostrados, foram coletadas cinco amostras para a determinação da K(o) em permeâmetro de carga constante, ou seja, cinco repetições por local amostrado. As amostras de solo com estrutura deformada foram acondicionadas em sacos plásticos e coletadas em quantidade suficiente para as determinações dos ensaios de textura do solo e densidade de partículas. A textura do solo foi determinada com três repetições, e a densidade de partículas com cinco. A densidade do solo foi determinada nas mesmas amostras utilizadas para a determinação da condutividade hidráulica saturada, como também a porosidade do solo.

\section{DETERMINAÇÕES}

As amostras foram coletas e transportadas para o Laboratório de Engenharia Ambiental da UNIFRA, Setor de Solos, onde foram realizadas as determinações a seguir.

\section{I Textura dos solos}

As frações granulométricas dos solos foram determinadas pelo método do Densímetro, conhecido como método do hidrômetro, conforme metodologia descrita por BOUYOCOS (1926). Baseando-se no princípio de que as partículas em suspensão (silte e argila) interferem na densidade ao liquido.

\subsection{Densidade de partículas (Dp)}

A densidade de partículas foi determinada de acordo com a Norma Técnica NBR 6508 - "Determinação da massa específica"- Método do Picnômetro (ABNT, 1984b) conforme a equação 1:

sendo:

$$
\mathrm{Dp}=\mathrm{Ms} / \mathrm{Vs}
$$

Dp a densidade das partículas (g.cm-3);

ms a massa dos sólidos (g);

Vs o volume dos sólidos $(\mathrm{cm} 3)$.

5.3 Densidade do solo (Ds)

A densidade do solo foi determinada de acordo com o Método do Anel Volumétrico (EMBRAPA, 1997), usando a equação 2:

$$
\mathrm{Ds}=\mathrm{Ms} / \mathrm{Vt}
$$

sendo:

Ds a densidade do solo (g.cm-3);

Ms a massa do solo (g);

Vt o volume total da amostra (cm3). 


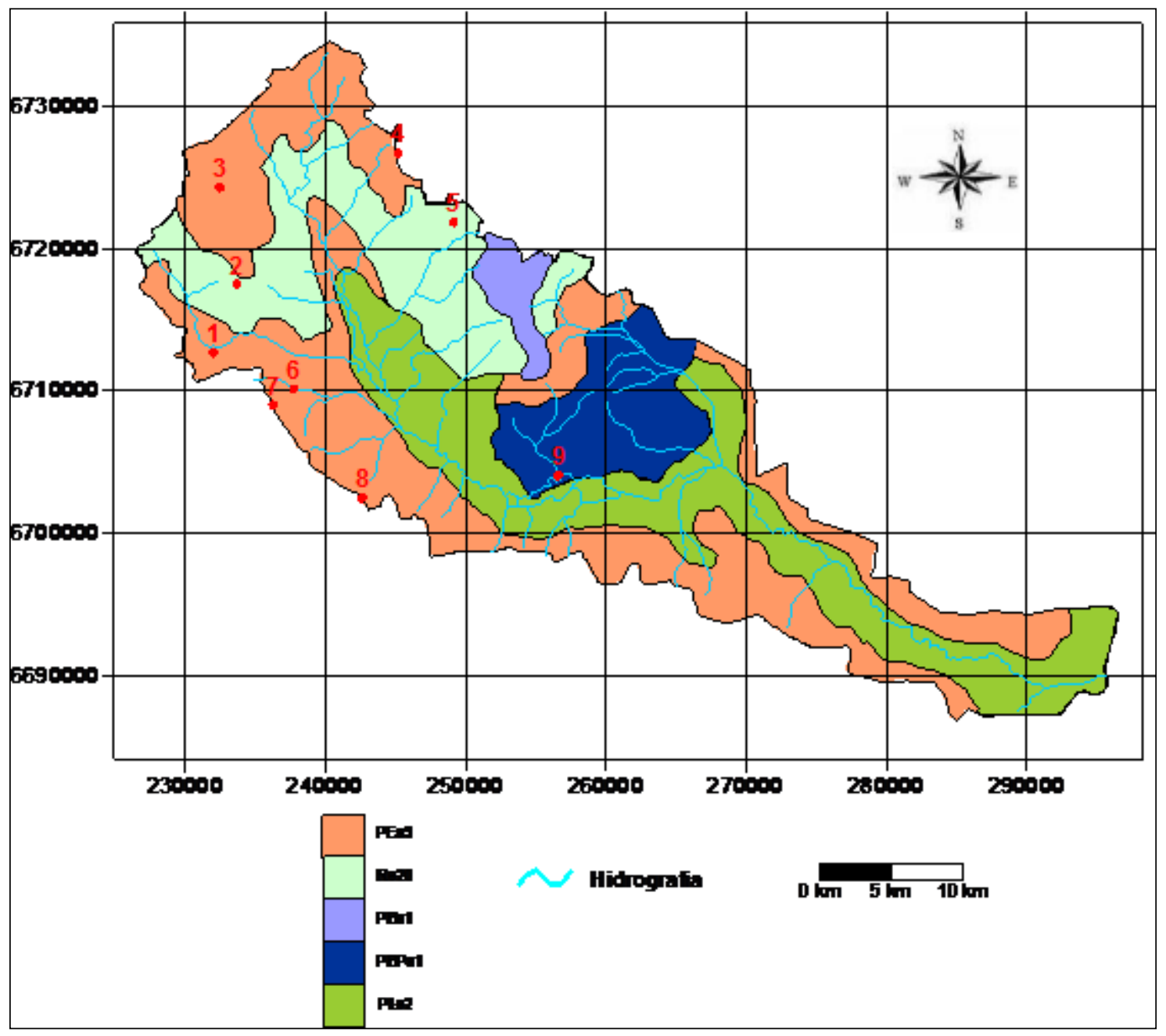

Figura 1. Localização dos pontos de amostragem de solos na Bacia Hidrográfica do RioVacacaí-Mirim-RS.

\subsection{Porosidade total $(\mathrm{Pt})$}

Nas mesmas amostras utilizadas para a determinação da densidade do solo, foram determinadas a porosidade total e o índice de vazios do solo, usando as equações apresentadas por STANCATI et al. (1981). O índice de vazios foi obtido pelo emprego da equação 3 :

sendo:

$$
\mathrm{e}=(\mathrm{Dp} / \mathrm{ds})-1
$$

e o índice de vazios (adimensional);

$\mathrm{Dp}$ a densidade das partículas do solo (g.cm-3);

Ds a densidade do solo (g.cm-3).

A porosidade total calculada mediante a aplicação da equação 4 :

$$
\mathrm{n}=(\mathrm{e} / 1+\mathrm{e}) \times 100
$$

$$
\text { sendo: }
$$

$\mathrm{n}$ a porosidade total do solo (\% Vol.); e o índice de vazios do solo (adimensional).

\subsection{Micro e macroporosidade}

Para determinação da micro e macroporosidade foi utilizado o método da Mesa de Tensão descrita por (OLIVEIRA, 1968), segundo as equações 5 e 6 :

$$
\begin{aligned}
& \text { MACROPOROSIDADE }=(\mathrm{P} 1-\mathrm{P} 2) \\
& \mathrm{x} 100 / \mathrm{V} \\
& \mathrm{e}
\end{aligned}
$$

$$
\begin{aligned}
& \text { MICROPOROSIDADE }=(\mathrm{P} 2-\mathrm{P} 3) \mathrm{x} \\
& \text { 100/V } \\
& \text { sendo: }
\end{aligned}
$$

P1 a massa do solo saturado com água (g); P2 a massa da amostra após ser submetida a uma tensão de $60 \mathrm{~cm}$ de coluna d'água (g). P3 a massa da amostra seca em estufa a $1050 \mathrm{C}(\mathrm{g})$;

$\mathrm{V}=$ volume do cilindro $(\mathrm{cm} 3)$.

\subsection{Condutividade hidráulica do solo saturado} $(\mathrm{K}(\mathrm{o}))$

A condutividade hidráulica do solo satu- 
rado foi determinada usando-se o permeâmetro de carga constante, seguindo a metodologia descrita por EMBRAPA (1997), conforme expresso pela equação 7: ) $\mathrm{K}(0)=(\mathrm{Q} \cdot \mathrm{L} / \mathrm{A} \cdot \mathrm{H} . \mathrm{t}$

[7]

sendo:

$\mathrm{K}(\mathrm{o})$ a condutividade hidráulica do solo saturado (cm.h-1);

Q volume de água percolado na amostra de solo contida no anel, ou a média das duas leituras quando há variação $(\mathrm{cm} 3)$;

$\mathrm{L}$ altura do anel preenchido com solo em (cm);

A área da secção transversal do anel do cilindro em (cm2);

t tempo (h);

$\mathrm{H}$ carga hidráulica $(\mathrm{cm})$.

\section{ANÁLISE ESTATÍSTICA}

A análise estatística dos dados referentes aos atributos físicos e hídricos do solo foi por meio da análise da variância, considerando o experimento em delineamento inteiramente casualizado com nove tratamentos e quatro repetições. Para comparação das médias foi aplicando o Teste de Tukey a $5 \%$ de probabilidade.

A análise de correlação entre os atributos do solo determina um valor que expressa uma medida numérica do grau de relação encontrada entre eles. Denomina-se simples a análise de correlação ou de regressão linear que abrange apenas duas propriedades do solo simultaneamente.

Utilizando-se os valores médios dos parâmetros determinados para cada solo estudado, foram realizadas análises de correlação e análises de regressão linear simples para os solos amostrados da bacia hidrográfica do Rio Vacacaí-Mirim.

\section{RESULTADOS E DISCUSSÃO}

A composição granulométrica do solo é uma característica inerente ao solo que possui grande importância no estudo do seu comportamento físico e hídrico. Vários fatores físico-hídricos do solo são influenciados pelo teor de argila, tais como o estado de energia da água no solo, o fluxo não saturado, a porosidade e a densidade do solo (RIBEIRO, 2005). Assim sendo, os resultados mostraram que o meio físico utilizado para a realização do presente trabalho pode ser caracterizado como heterogêneo, devido às grandes variações granulométricas ao longo na bacia hidrográfica.

São apresentados na Tabela 2 os resultados médios da granulométrica dos solos estudados. $\mathrm{Na}$ Tabela 3 são apresentados os resultados de condutividade hidráulica saturada como também as respectivas densidades e porosidades dos solos.

Quanto aos valores de densidade de partículas, verificou-se que todos os pontos amostrados estão iguais ou acima do valor universal geralmente adotado, 2,65 g.cm-3. Indicando a existência de partículas mais densas que o quartzo, que influenciou o valor médio para acima do valor médio universal (MOTA, 2008).

O maior valor observado de $\mathrm{Dp}$ foi para o solo de textura franco arenosa, enquanto que o solo de tex-

Tabela 2. Valores médios das frações granulométricas e classificação dos solos.

\begin{tabular}{ccccc}
\hline \multirow{2}{*}{ Pontos } & \multicolumn{3}{c}{ Granulometria } & \multirow{2}{*}{ Classe Textural $^{(2)}$} \\
\cline { 2 - 4 } & Areia & Silte & Argila & \\
\hline 1 & $-------------o \%$ & \\
2 & $92,2 \mathrm{a}^{(1)}$ & $4,4 \mathrm{a}$ & $3,3 \mathrm{a}$ & Arenosa \\
3 & $44,5 \mathrm{~b}$ & $37,2 \mathrm{~d}$ & $18,3 \mathrm{c}$ & Franca \\
4 & $24,4 \mathrm{c}$ & $15,5 \mathrm{~b}$ & $60,0 \mathrm{f}$ & Muito argilosa \\
5 & $16,7 \mathrm{~d}$ & $28,9 \mathrm{c}$ & $54,4 \mathrm{e}$ & Argilosa \\
6 & $33,3 \mathrm{e}$ & $27,7 \mathrm{c}$ & $38,9 \mathrm{~d}$ & Franco-argilosa \\
7 & $76,7 \mathrm{f}$ & $12,2 \mathrm{~b}$ & $11,1 \mathrm{~b}$ & Franco-arenosa \\
8 & $66,7 \mathrm{~g}$ & $13,3 \mathrm{~b}$ & $20,0 \mathrm{c}$ & Franco-argilo arenosa \\
9 & $80,6 \mathrm{~h}$ & $6,1 \mathrm{a}$ & $13,3 \mathrm{~b}$ & Franco-arenosa \\
\hline
\end{tabular}


Tabela 3. Valores médios de condutividade hidráulica saturada (cm.h-1), densidade do solo e de partícula (g.cm-3) e porosidade total, micro e macroporosidade (\%) dos solos amostrados na bacia hidrográfica do Rio Vacacaí-Mirim.

\begin{tabular}{|c|c|c|c|c|c|c|}
\hline \multirow{2}{*}{$\begin{array}{c}\text { Pontos amostrados e } \\
\text { Textura }\end{array}$} & \multirow{2}{*}{$K_{(0)}$} & \multicolumn{2}{|c|}{ Densidade } & \multicolumn{3}{|c|}{ Porosidade } \\
\hline & & Ds & Dp & Pt & Micro & Macro \\
\hline & $--\left(\mathrm{cm} \cdot \mathrm{h}^{-1}\right)--$ & \multicolumn{2}{|c|}{-----(g.cm $\left.{ }^{-3}\right)^{----}$} & \multicolumn{3}{|c|}{---------(\%Vol)----------- } \\
\hline 1. Arenosa & $0,02 a^{(1)}$ & $1,58 d$ & $2,75 b$ & $42,5 b c$ & $37,6 \mathrm{~d}$ & $4,9 a$ \\
\hline 2. Franca & $2,96 d$ & $1,12 \mathrm{a}$ & $2,66 a$ & $57,9 f$ & $45,8 f$ & $12,1 \mathrm{de}$ \\
\hline 3. Muito argilosa & $0,70 b$ & $1,54 d$ & $2,74 b$ & $43,9 \mathrm{~cd}$ & $37,1 d$ & $6,8 a$ \\
\hline 4. Argilosa & $0,36 a b$ & $1,52 \mathrm{~cd}$ & $2,79 b c$ & $45,5 \mathrm{de}$ & $41,6 e$ & $3.9 a$ \\
\hline 5. Franco-argilosa & $1,42 \mathrm{c}$ & $1,39 b$ & $2,65 a$ & $47,3 e$ & $39,1 d$ & $8,2 b c$ \\
\hline 6. Franco-arenosa & $0,14 a b$ & $1,68 \mathrm{e}$ & $2,78 b$ & $39,4 a$ & $32,1 \mathrm{c}$ & $7,2 a b c$ \\
\hline 7. Franco-argilo arenosa & $0,21 a b$ & $1,46 b c$ & $2,67 a$ & $48,2 e$ & $38,7 d$ & $9,5 c d$ \\
\hline 8. Franco-arenosa & $0,08 a$ & $1,80 f$ & $2,86 c$ & $39,1 a$ & $24,3 b$ & $14,8 \mathrm{e}$ \\
\hline 9. Areia-franca & $0,17 a b$ & $1,78 f$ & $2,78 b$ & $39,7 a b$ & $19,1 \mathrm{a}$ & $20,7 f$ \\
\hline
\end{tabular}

tura franca foi o que apresentou o menor valor de $\mathrm{Dp}$ (Tabela 3). Segundo RIBEIRO (2005), o menor valor de $\mathrm{Dp}$ em solo de textura franca se justifica por conter maior conteúdo de matéria orgânica em sua composição. Segundo BRADY (1989), pode-se constatar que a densidade de partículas será tanto menor quanto maior for o conteúdo de matéria orgânica no solo.

A densidade do solo é um dos parâmetros que pode ser utilizada para inferir sobre as condições de compactação do solo, sendo muito usada na avaliação do estado estrutural, servindo como subsídio para definir as condições de manejo adequado do solo. Em sistema de plantio direto, por exemplo, as camadas compactadas pelas máquinas agrícolas provocam redução na infiltração de água. Tais camadas podem ser facilmente detectáveis pela densidade do solo. Lavouras cultivadas sob plantio direto apresentam, normalmente, maior resistência mecânica à penetração e maior densidade do solo na profundidade entre $8 \mathrm{~cm}$ e $12 \mathrm{~cm}$ (CARTER et al., 1999; CORRECHEL et al., 1999). O preparo e a compactação alteram o sistema poroso do solo e, consequentemente, afetam os processos hídricos nele ocorrentes.

O solo de textura franca foi o que apresentou o menor valor de densidade do solo (Tabela 3). Constatouse também que, nesse solo, o maior valor de porosidade total proporcionou uma maior permeabilidade ao fluxo de água no perfil em relação aos demais, considerandose as mesmas condições topográficas e uso do solo. Ou seja, o aumento de densidade provoca redução do espaço de poros do solo, e a macroporosidade é reduzida em maior proporção do que a porosidade total (SILVA et al. 2000).

De acordo com Conte et al.(2007), a porosidade total é inversamente proporcional à densidade do solo, em que os maiores valores de porosidade total correspondem aos menores valores de Ds. Tal desempenho foi evidenciado para os solos estudados, somente o solo franco-argilo-arenoso que não teve esse comportamento, o que pode ser explicado pela atividade biológica, ciclos de umedecimento e secagem ou até mesmo o revolvimento do solo que age no sentido de diminuir a Ds na superfície do solo (SILVA et al. 2000).

O solo com textura franca foi o que apresentou o maior valor de condutividade hidráulica saturada, devido ao menor valor encontrado para densidade do solo e maior valor de porosidade total para este solo, resultado de sua estrutura, o que é evidenciado também no trabalho de Ribeiro et al. (2007).

De modo geral, os maiores valores de condutividade hidráulica saturada tendem a ser encontrados juntamente com os maiores valores de porosidade total. Tal comportamento não foi observado para os solos estudados, com exceção dos solos com textura franca e franco-argiloso. Isso pode estar relacionado ao tipo de estrutura e o sistema de uso do solo. Considerando-se que o fluxo saturado da água no solo ocorre nos macroporos e avaliando esse parâmetro na Tabela 3 constatou-se que nem sempre os solos com maior macroporosidade apresentaram altos valores 
de condutividade hidráulica saturada. Esse comportamento pode ser atribuído a problemas de degradação da estrutura no caso de solos cultivados, alterando a continuidade dos poros ou a problemas ocorridos na determinação do atributo.

O solo de textura franca foi o que apresentou o maior valor de condutividade hidráulica saturada, confirmando com o menor valor de densidade do solo e maior valor de porosidade total encontrado para este solo, com valores de macroporosidade de $12 \%$ em volume. De modo geral, os solos avaliados apresentam baixos valores de macroporosidade nessa camada. Em princípio, um solo considerado fisicamente ideal deveria ter em torno de $25 \%$ de macroporos. Esse comportamento provavelmente pode influenciar para o aumento do volume de escoamento superficial de água na bacia hidrográfica. Em solos utilizados com agricultura e pecuária também se constatou baixos valores de macroporosidade. Segundo os trabalhos de SILVA \& KATTO (1997) e ANKENY et al. (1990), trabalhando com diferentes sistemas de cultivo, constataram que os sistemas utilizados alteraram a porosidade e as propriedades hidráulicas dos solos cultivados principalmente nas camadas superficiais do solo.

Uma explicação para a diminuição na condutividade hidráulica saturada dos solos pode ser pelo provável bloqueio dos poros condutores devido ao cultivo convencional do solo por muitos anos. $\mathrm{O}$ processo de aração e gradagem alteram a estrutura do solo, principalmente degradando-a (BRADY, 1989). Além desse processo, provavelmente tenha ocorrido também a migração de partículas de silte e argila das camadas mobilizadas para o local denominado de péde-arado, situado imediatamente abaixo da camada arada. Cabendo destacar ainda que essas alterações nas condições químicas de solos cultivados, variações do $\mathrm{pH}$ e da concentração crítica de floculação das partículas podem causar modificações na dispersão da fração argila, degradando a estrutura original do solo (BENITES e MENDONÇA, 1998).

As características físicas e hídricas do solo como: textura, estrutura e porosidade influenciam diretamente a condutividade hidráulica saturada do solo, como também a presença de raízes de plantas, atividade microbiana, rachaduras localizadas, entre outros fatores (QUEIROZ, 1995).

\section{CORRELAÇÕES DA CONDUTIVIDADE HIDRÁULICA SATURADA (K(O)) COM OS ATRIBUTOS FÍSICOS DO SOLO}

Observa-se na Tabela 4 que a porosidade total e a percentagem de silte apresentaram correlação forte positiva com $\mathrm{K}(\mathrm{o})$, enquanto que a Ds solo apresentou correlação forte negativa, contudo, significativa ao nível de 5\%. Nenhum dos atributos físicos dos solos apresentou alta correlação com a condutividade hidráulica saturada (SANTOS, 2007).

As frações areia e argila dos solos não apresentaram correlação significativa com condutividade hidráulica saturada. Tal fato pode ser explicado porque a estabilidade dos agregados ocorre em função da aproximação e cimentação de partículas de natureza mineral e orgânica do solo, sendo que a intensidade destes mecanismos influencia a resistência das unidades estruturais perante as forças desagregantes (KEMPER; CHEPIL, 1965).

Em condições de alta produção de fitomassa, são favorecidos os mecanismos biológicos envolvidos na estabilização dos agregados (BASSO; REINERT, 1998). Assim, a agregação é afetada pela matéria orgânica, que favorece a cimentação. A partir do efeito da matéria orgânica sobre a agregação do solo, indiretamente são afetadas outras características físicas do solo, como a densidade, a porosidade, a aeração, a capacidade de retenção e a infiltração de água, entre outras (BAVER et al., 1973).

Além disso, solos com diferentes classes texturais podem evidenciar uma distribuição contrastante na sua porosidade e, por consequência, na condutividade hidráulica saturada (RIBEIRO, 2005).

O efeito da estrutura, e em especial dos poros grandes, permite que um solo argiloso tenha valores de condutividade hidráulica saturada similar a solos arenosos. Segundo RIGHES et al. (2009), a taxa de infiltração de água no solo depende mais da estrutura do solo do que da textura. Solos argilosos, bem estruturados, podem apresentar $\mathrm{K}$ (o) mais elevada do que solos de textura arenosa. Portanto, determinar a $\mathrm{K}(0)$ a partir de propriedades do solo mais facilmente obtidas é um processo complexo que envolve todos os fatores que influenciam nestas propriedades e nas relações entre elas.

Os solos com elevada percentagem de microporos apresentaram menores valores de condutividade hidráulica saturada o que significa conduzir menor volume de água para as camadas inferiores do solo, ou seja, espera-se que microporosidade e condutividade hidráulica saturada sejam inversamente proporcionais. Todavia, a correlação encontrada neste trabalho entre microporosidade e condutividade hidráulica saturada não foi significativa. Tal fato evidencia a importância de se levar em consideração a continuidade dos microporos na avaliação do comportamento hidráulico dos solos, em virtude de poros menores, porém contínuos, permitirem maior fluxo de água e solutos do que poros maiores descontínuos no perfil do solo (RIGHES et al. .2009). 
Tabela 4. Coeficientes de correlação simples entre a condutividade hidráulica saturada $\mathrm{K}(\mathrm{o})$ e os atributos físicos dos solos coletados na bacia hidrográfica do Rio Vacacaí-Mirim.

\begin{tabular}{cc}
\hline Atributos Físicos & Coeficiente de Correlação \\
\hline $\mathrm{K}_{(\mathrm{o})} \times$ areia & $-0,4447$ \\
$\mathrm{~K}_{(\mathrm{o})} \times$ silte & $0,7836^{*}$ \\
$\mathrm{~K}_{(\mathrm{o})} \times$ argila & 0,1584 \\
$\mathrm{~K}_{(\mathrm{o})} \times \mathrm{Ds}$ & $-0,8496^{*}$ \\
$\mathrm{~K}_{(\mathrm{o})} \times \mathrm{Dp}$ & $-0,5997$ \\
$\mathrm{~K}_{(\mathrm{o})} \times$ micro & 0,5621 \\
$\mathrm{~K}_{(0)} \times$ macro & 0,0669 \\
$\mathrm{~K}_{(\mathrm{o})} \times \mathrm{Pt}$ & $0,8524^{*}$ \\
\hline
\end{tabular}

Uma explicação para os macroporos não possuírem distribuição assimétrica pode ser a de que o movimento da água nos macroporos não segue a teoria capilar, devido ao diâmetro do macroporo. Por isso, pode-se formar um filme de água na parede do poro, quando este poro não estiver completamente preenchido com líquido. Assim, macroporos contribuem para o fluxo de água nos poros com pequeno ou nenhum fluxo, atuando como um reservatório transitório que permite o movimento da água mesmo quando o solo não está totalmente saturado (BEVEN \& GERMANN, 1982). A relação entre a condutividade hidráulica saturada e a macroporosidade dependerá também de outros fatores, uma simples análise de correlação não poderá descrever totalmente a relação entre estas variáveis.

\section{ANÁLISES DE REGRESSÃO ENTRE A CONDUTIVIDADE HIDRÁULICA SATU- RADA (K(O)) E OS ATRIBUTOS FÍSICOS DE CADA TIPO DE SOLO}

Procurando identificar melhor a relação entre a condutividade hidráulica do solo saturado com os demais atributos físicos para cada tipo solo, foram realizadas análises de regressão linear simples. Ressalta-se que são vários os fatores que agem conjuntamente no processo do movimento da água no solo.

Considerando todos os solos estudados, nenhum dos atributos físicos relacionou-se significativamente com a condutividade hidráulica saturada a 1\%. Além disso, considerando o nível de $5 \%$ de significância, a condutividade hidráulica saturada correlacionou-se com a percentagem de silte, densidade do solo e porosidade total. O que faz complementar que, se tratando de alternadas frações granulométricas em um meio físico bastante heterogêneo, não se podem estimar com apenas duas variáveis a condutividade hidráulica saturada do solo.

Na Figura 2 pode-se observar o comportamento da densidade do solo em relação a condutividade hidráulica saturada. A correlação moderada entre essas duas variáveis indica que $72,2 \%$ da variação da condutividade hidráulica saturada é explicada pela densidade do solo para todos os solos estudados, ou seja, elevados valores de $\mathrm{K}(\mathrm{o})$ foram encontrados em solos com menores valores de Ds, o que reflete a importância da continuidade dos macroporos para o fluxo saturado de água. Porém, o esclarecimento para isso não é muito significativo e claro, na verdade se contrapõe ao que se entende sobre a influência da densidade do solo na natureza do sistema estrutural dos poros. Segundo MESQUITA et al. (2004), nas camadas superficiais, geralmente, há maior variação na densidade do solo devido ao manejo, o que pode propiciar a formação de poros com diâmetros maiores, os quais permitem maiores valores de condutividade hidráulica saturada. Entretanto, esses poros podem não influenciar muito na densidade do solo.

Assim como para densidade do solo, também já se havia constatado uma significativa correlação entre condutividade hidráulica saturada e porosidade total (Figura 3), indicando a possibilidade de estimar K(o) a partir da Pt. Isso se deve ao fator de que $72,6 \%$ da variação da porosidade total é explicada pela condutividade hidráulica saturada, ou seja, quanto menores forem os valores de $\mathrm{Pt}$, menor será a $\mathrm{K}(\mathrm{o})$. De modo geral, os maiores valores de $\mathrm{K}(\mathrm{o})$ são encontrados jun- 


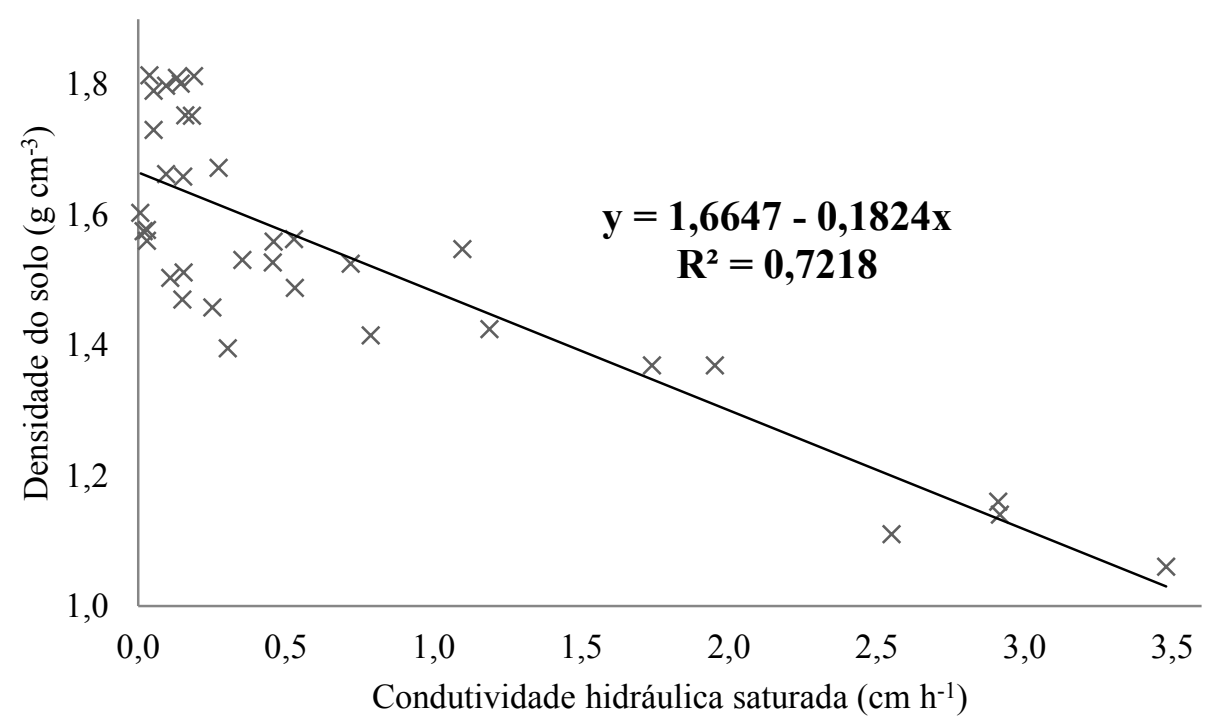

Figura 2. Relação entre a condutividade hidráulica saturada e a densidade dos solos coletados na bacia hidrográfica do Rio VacacaíMirim.

tamente com os maiores valores de porosidade total. Entretanto, Bouma (1982) relata que pequenos poros podem conduzir mais quando são poros contínuos, enquanto poros maiores em uma dada seção podem não contribuir para o fluxo, quando apresentam descontinuidade no solo todo.

A maior correlação entre todos os parâmetros físicos do solo ocorreu entre densidade do solo e porosidade total (Figura 4), apresentando correlação significativa a $1 \%$. Houve correlação negativa entre a Ds e Pt, indicando que $92,4 \%$ da variação da Porosidade total é explicada pela densidade do solo. Isso permite afirmar que quanto maior a Ds menor será a $\mathrm{Pt}$ do solo. Esses mesmos resultados podem ser verificados em trabalho desenvolvido por RIBEIRO et al. (2007), em que os menores valores de índice de vazios correspondem principalmente aos solos arenosos, indicando que suas partículas sólidas tendem a estar arranjadas em íntimo contato, justificando os menores valores de porosidade total e maiores valores de densidade do solo encontrados para estes solos.

Os baixos valores de coeficiente de correlação encontrados para $\mathrm{K}$ (o) e areia, argila, macro, microporosidade e densidade de partícula, nos indica que não seria possível estimar a $\mathrm{K}(\mathrm{o})$ em função destas variáveis separadamente, não permitindo estimar o fluxo de água nas camadas superficiais dos solos analisando a $\mathrm{K}(\mathrm{o})$ separadamente destes atributos.

Assim sendo, a dependência entre a $\mathrm{K}(\mathrm{o})$ dos atributos físicos dos solos não pode ser obtida direta-

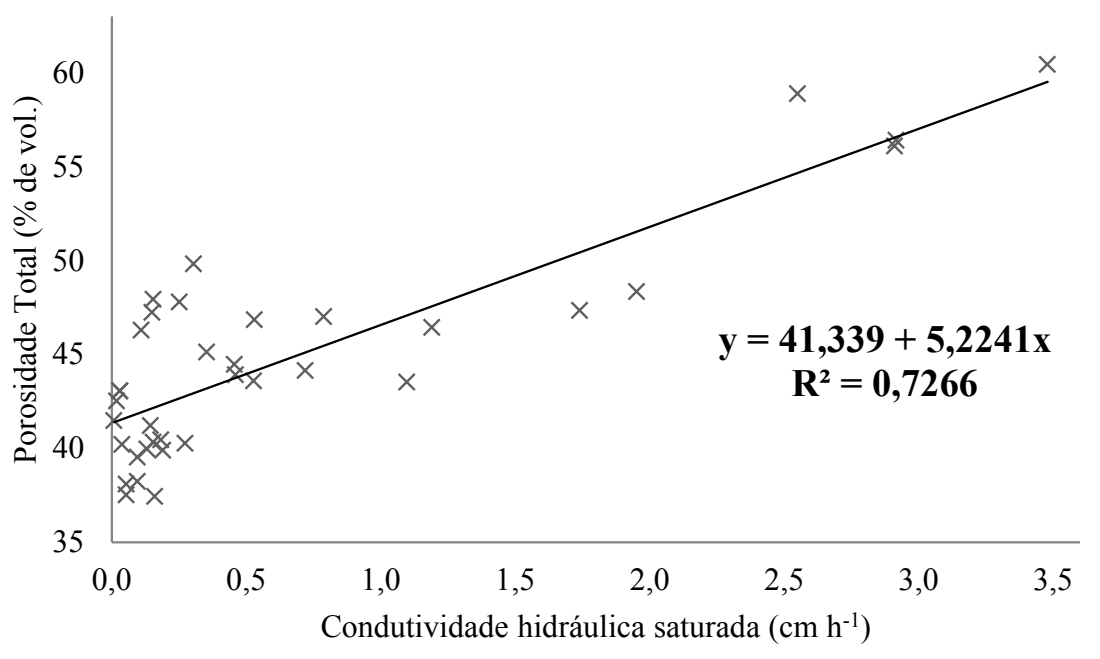

Figura 3. Relação entre a condutividade hidráulica saturada e a porosidade total dos solos coletados na bacia hidrográfica do Rio Vacacaí-Mirim. 


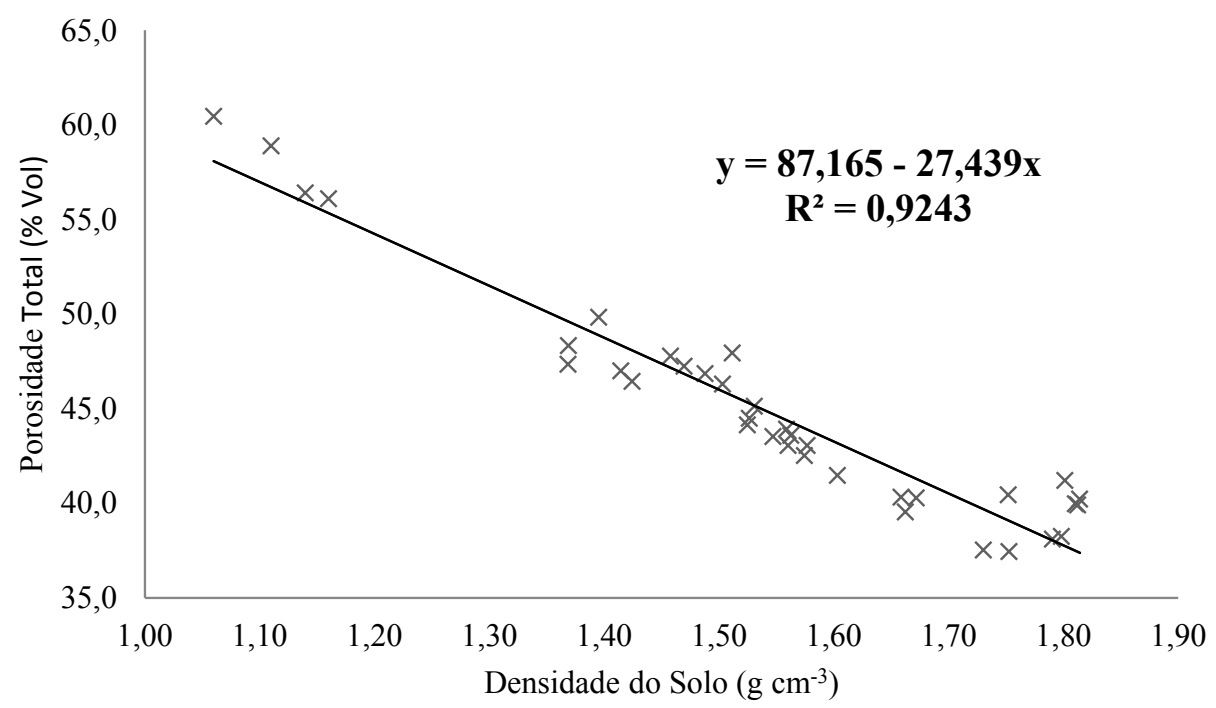

Figura 4. Relação entre a densidade do solo e a porosidade total.

mente por uma simples correlação. Na pratica, são vários os fatores que agem conjuntamente no processo do movimento da água no solo. Segundo MESQUITA et al. (2004), a K(o) depende em grande parte da forma e continuidade dos poros, e pode variar de um local a outro, diferindo também para as distintas orientações do solo, o que pode levar à assimetria do solo. Ou seja, a assimetria, geralmente detectada somente para a $\mathrm{K}(\mathrm{o})$ do solo e não para as demais propriedades relacionadas à porosidade, permite inferir que descrever a porosidade somente a partir da $\mathrm{K}(\mathrm{o})$ pode levar a erros provenientes de causas não conhecidas.

\section{CONCLUSÃO}

a) Dentre os solos analisados na bacia hidrográfica do Rio Vacacaí Mirim, os solos com texturas franca e franco-argilosa são os que apresentam condições mais favoráveis para a o fluxo saturado de água no perfil do solo.

b) Dos solos avaliados na bacia hidrográfica do Rio Vacacaí Mirim há correlação direta entre porosidade total e condutividade hidráulica saturada.

\section{REFERÊNCIAS}

ANKENY, M. D.; KASPAR, T. C.; HORTON, $\mathrm{R}$. Caracterization of tillage and traffic effects on unconfined infiltration measurement. Revista Soil Science Societyof American Journal Vol.54, p.837840, 1990.

ASSOCIAÇÃO BRASILEIRA DE NORMAS TÉC-
NICAS. NBR 6508. Determinação da massa específica. Rio de Janeiro: ABANT, $1984 b$.

BAVER, L. D.; GARDNER, W. H.; GARDNER, W. R. Fisica de Suelos. Mexico: Centro Regional de Ayuda Tecnica, 1973. 529 p.

BASSO, C. J.; REINERT, D. J. Variação da agregação induzida por plantas de cobertura de solo no inverno e plantio direto de milho em um solo podzólico. Revista Ciência Rural, Vol. 28, n. 4, p. 567-571, out./dez. 1998.

BELTRÁN, J. M. Drenaje agricola. Madrid: Ministerio da Agricultura, Pesca y Alimentacion, 1986. $239 \mathrm{p}$.

BENITES, V. M.; MENDONÇA, E. S. Propriedades eletroquímicas de um solo eletropositivo influenciadas pela adição de diferentes fontes de matéria orgânica. Revista Brasileira de Ciência do Solo, Vol.22, n.2, p. 215-221, 1998.

BEVEN, K.; GERMANN, P. Macropores and water flow in soils. Revista Water Resources Research, Vol.18, n.5, p.1311-1325, 1982.

BOUYOUCOS, G. J. Estimation of the Colloidal Materials in Soils. Revista Science, Vol. 64, p 362364. 1926.

BRADY, N. C. Elementos da Natureza e Propriedades dos Solos. Rio de Janeiro: Freitas Bastos, $1989.716 \mathrm{p}$. 
BOUMA, J. Measuring the conductivity of soil horizons with continuous macropores. Soil Science Society of America Journal, Vol.46, p.438-441, 1982.

CARTER, M. R.; ANGERS, D.A.; TOPP, G. C. Characterizing equilibrium physical condition near the surface of a fine sandy loam under conservation tillage in a humid climate. Soil Science, Vol. 164, p. 101-110, 1999.

CORRECHEL, V.; SILVA, A. P.; TORMENA, C. A. Influência da posição relativa à linha de cultivo sobre a densidade do solo em dois sistemas de manejo do solo. Revista Brasileira de Ciência do Solo, Vol.23, p.165-173, 1999.

CONTE, O.; LEVIEN, R.; TREIN, C. R.; CEPIK, C. T. C.; DEBIASI, H. Demanda de tração em haste sulcadora na integração lavourapecuária com diferentes pressões de pastejo e sua relação com o estado de compactação do solo. Revista Engenharia Agrícola, Vol.27, n.1, p.220-228, 2007.

EMPRESA BRASILEIRA DE PESQUISA AGROPECUÁRIA. Manual de métodos de análise do solo. Centro Nacional de Pesquisa de Solos. Rio de Janeiro, 1997. 212 p.

EMBRAPA - EMPRESA BRASILEIRA DE PESQUISA AGROPECUÁRIA. Sistema Brasileiro de Classificação de Solos. Brasília: 1999. 412 p.

\section{INSTITUTO BRASILEIRO DE GEOGRAFIA E} ESTATÍSTICA, IBGE. Mapa exploratório de solos do Estado do Rio Grande do Sul. Rio de Janeiro:I BGE, 2002. Escala 1:1000000.

KEMPER, W. D.; CHEPIL, W. S. Size distribution of aggregation. In: BLACK, C. A. (ed.)

Methods of soil analysis. Madison: American Society Agronomy, 1965. p. 499-510.

LAMBE, T. W.; WHITMAN, R. V. Mecânica de suelos. México: Editorial Limusa S.A., 1974.

LEMOS, R. C.; SANTOS, R. D. Manual de descrição e coleta de solo no campo. Campinas: Sociedade Brasileira de Ciência do Solo/Embrapa-SNLCS, 1984. 46p.

MARQUES, J. D. de O. Horizontes pedogenéticos e sua relação com camadas hidráulicas do solo. 2000. 86f. Dissertação (Mestrado em Agronomia) - Programa de Pós-Graduação em Agronomia, Escola
Superior de Agricultura de Luiz de Queiroz, Piracicaba, 2000.

MARQUES, J. D.; TEIXEIRA, W. G. ; REIS, A. M. ; CRUZ JUNIOR, O. ; MARTINS, G. C. Avaliação da condutividade hidráulica saturada utilizando dois métodos de laboratório numa topossequência de solos amazônicos com diferentes coberturas vegetais. Revista Acta Amazônica, Vol.38, p.193-206, 2008.

MESQUITA, M. G. B. F.; MORAES, S. O. A Dependência Entre um Condutividade hidráulica saturada e Atributos físicos do solo. Revista Ciência Rural, Vol.34, n.3, p. 963-969, 2004.

MOTA, J. C. A.; ASSIS JUNIOR, R. N.; AMARO FILHO, J.; LIBARDI, P. L. Algumas propriedades físicas e hídricas de três solos na Chapada do Apodi, $\mathrm{RN}$, cultivados com melão. Revista Brasileira de Ciência do Solo, Vol.32, n.1, p. 49-58, 2008.

OLIVEIRA, L. B. Determinação da macro e microporosidade pela mesa de tensão em amostras de solo com estrutura indeformada. Revista Pesquisa Agropecuária Brasileira, Vol.3, p.197-200, 1968.

QUEIROZ, J. E. Parâmetros hidrodinâmicos de um solo de várzea para fins de drenagem subterrânea. 1995, 167f. Tese (Doutorado em Irrigação e Drenagem), Programa de Pós-Graduação Engenharia Agrícola, Escola Superior de Agricultura Luiz de Queiroz, Piracicaba. 1995.

REICHARDT, K. A água em sistemas agrícolas. São Paulo: Manole, 1990. 188p.

RICHART, A.; TAVARES FILHO, J.; BRITO, O. R.; LLANILLO, R. F.; FERREIRA, R. Compactação do solo: Causas e efeitos. Revista Semina - Ciências Agrárias, Vol. 26, n.3, p.321-344, 2005.

RIBEIRO, K. D. Influência da distribuição de vazios na condutividade hidráulica do solo saturado. 2005, 56f. Dissertação (Mestrado em Engenharia Agrícola) - Programa de Pós-Graduação em Engenharia Agrícola, Universidade Federal de Lavras, Lavras, 2005.

RIBEIRO, K. D.; MENEZES, S. M.; MESQUITA, M. G. B. F. SAMPAIO, F. M. T. Propriedades físicas do solo, influenciadas pela distribuição de poros, de seis classes de solos da região de Lavras-MG. Revista Ciência e Agrotecnologia, Vol.31, n.4, p.1167-1175, 2007. 
RIGHES, A. A.; SILVA, R. F. Água e educação: Princípios e estratégias de uso e conservação. Santa Maria: Centro Universitário Franciscano, 2009. 269 p.

SANTOS, C. Estatística Descritiva - Manual de Auto -aprendizagem. Lisboa: Edições Sílabo: 2007. 264 p.

SILVA, C. L.; KATO, E. Efeitos do selamento superficial na condutividade hidráulica saturada da superfície de um solo sob cerrado. Revista Pesquisa Agropecuária Brasileira, Vol.31, p.593-597, 1997.

SILVA, V. R.; REINERT, D. J.; REICHERT, J. M. Resistência mecânica do solo à penetração influenciada pelo tráfego de uma colhedora em dois sistemas de manejo do solo. Revista Ciência Rural, Vol.30, n.5, p.795-801, 2000.

STANCATI, G.; NOGUEIRA, J. B.; VILAR, O. M. Ensaios de laboratório em Mecânica dos Solos. São Carlos: Universidade de São Paulo/Escola de Engenharia de São Carlos/ Departamento de Geotecnia, 1981. $30 \mathrm{p}$. 